\title{
Evolving California genotypes of Avena barbata are derived from multiple introductions but still maintain substantial population structure
}

Multiple introductions are thought to enhance the chance of successful colonization, in part because recombination may generate adaptive variation to a new environment. Avena barbata (slender wild oat) is a successful colonist in California, historically noted for striking genetic divergence into two multilocus genotypes, but is still undergoing adaptive change. We sought to understand whether multiple introductions might be contributing to this change. We used cpDNA phylogeography of $A$. barbata within its home range and in its invaded range in California to determine the minimum number of separate introductions, and the spatial distribution of these introduced lineages. We collected from sites throughout the state of California, where it is an invasive species. Accessions from a representative portion of $A$. barbata's full native range were obtained from germplasm repositories. We sequenced seven intergenic chloroplast DNA loci for $A$. barbata individuals both in California (novel geographic range) and its ancestral range. 204 individuals were assayed for chloroplast haplotype within California using single strand conformational polymorphism SSCPs. Genome size was determined by flow cytometry. Californian accessions are tetraploid as expected, but their genome sizes were smaller than the Old World accessions. There were three haplotypes present in California that were identical to haplotypes in the native range. Within California, the presence of multiple haplotypes at a site was observed primarily in Northern and Central populations. Between populations there was still substantial structure with $\mathrm{F}_{\mathrm{ST}} \sim 0.33$, due to a shallow latitudinal cline caused by a preponderance of xeric haplotypes in Southern California. There was a minimum of three seed introductions to California. Recombination is thus likely to occur, and contribute to adaptation in new range in this highly-selfing, invader. 
1 Author names: Kate Crosby ${ }^{1}$, Taylor O. Stokes ${ }^{1}$, Robert G. Latta ${ }^{1}$

2 Affliations: 1. Department of Biology, Dalhousie University, Halifax, NS, CANADA B3H 4R2

3 Corresponding author: Kate Crosby (crosbyk@,dal.ca) 
12

13

14

15

16

17

18

19

20

21

22

23

24

25

26

27

28

29

30

31

32

33

34

35

36

37

38

39

40

41

42

43

44

45

46

47

\section{Introduction}

Introduced and invasive species are likely to have to adapt to novel conditions (Dlugosch \& Parker, 2008; Prentis et al., 2008), and the first requirement of adaptation is access to a pool of genetic variation. The pool of genetic variation can be increased through introductions from multiple sources. Typically, adaptive genetic variation is much reduced in the new range compared to the home range, as many invasive species reproduce primarily via selfing or are facultatively asexual during colonization of the new range (Baker, 1955; 1967; Price \& Jain, 1981; Barrett \& Colautti, 2008). During invasions, the main advantage of selfing is that individuals need not depend on pollinators or other conspecifics to pollinate with, for persistence or spread. Indeed, in selfing or clonal species, one or a few introductions could be enough to allow for successful establishment and persistence - even on a global scale (Le Roux et al., 2007). By contrast, outcrossing species generate new multilocus genotypes with each round of outcrossing, provided that enough individuals of different genotypes have been introduced that mates are available and to avoid inbreeding depression.

Self-fertilizing species typically suffer less from the effects of inbreeding depression than outcrossers (Husband \& Schemske, 1996), but they may still require adaptive genetic variation in order to respond to novel environmental conditions. It has been suggested that, multiple introductions of different genetic variants allow selfing species the opportunity for occasional outcrossing and recombination in new environments (Ellstrand \& Schierenbeck, 2000; Schierenbeck \& Ellstrand, 2009). Assessing the minimum number of introductions in a new environment is thus critical to evaluating how important the amount of genetic variation may be for self-fertilizing species in the new range, which will ultimately determine how much effective recombination is possible in the new range.

Californian populations of the highly-selfing (Marshall \& Allard, 1970), tetraploid (Hutchinson et al., 1983), invasive annual grass, Avena barbata Pott ex Link are thought to have been introduced from the Iberian Peninsula roughly two centuries ago during Spanish colonization (Jain \& Marshall, 1967; Garcia et al., 1989). Avena barbata became widely known for a number of pioneering observations in the 1970s (Clegg \& Allard, 1972; Allard et al., 1972; Hamrick \& Holden, 1979) which found that there were predominantly two multilocus genotypes of A. barbata in California. Each genotype was monomorphic for a set of five allozyme loci, and few recombinants were found. One genotype was found in moist environments, while the other occurred in more arid environments, a pattern repeated at both large (Clegg \& Allard, 1972; Allard et al., 1972) and small geographic scale (Hamrick \& Holden, 1979), leading to the interpretation that these represented locally adapted 'mesic' and 'xeric' ecotypes. The allozyme combinations characteristic of the original Californian genotypes were not found in native Iberian populations (Garcia et al., 1989). This suggests that recombination among separate genotypes was part of the evolutionary history of $A$. barbata in California.

Past experimental work in which a novel environment was imposed in the greenhouse demonstrated that recombination between the two genotypes produced a few hybrid recombinants that were more fit than the parents (Johansen-Morris \& Latta, 2006; 2008). Additionally, a previous four-year field common garden, reciprocal transplant experiment of parental genotypes to wet and dry environments found that the mesic genotype, and a few recombinants are consistently more fit than the xeric (Latta, 2009). Thus, the mesic could be displacing the xeric genotype, or a recombinant could be displacing both as the prominent genotype throughout 
48 California. Collectively, this evidence does not support the idea that the two genotypes are locally

49 adapted to moist and arid environments as Allard's work suggested (though we retain the names

50 'mesic' and 'xeric' here), but rather that adaptive change is still occurring in California. This

51 continuing evolution could be due to recombination between several different genetic variants as

52 demonstrated by Johansen-Morris \& Latta $(2006 ; 2008)$ and/or the superior fitness of one lineage

53 (likely the mesic) (Latta, 2009).

54 The first step in assessing the role of intermixing and recombination is to determine the

55 minimum number of introductions to California and their spatial distribution. We constructed a

56 cpDNA phylogeny of accessions from across $A$. barbata's native range as well as its invaded

57 range in California to determine the minimum number of introductions to California. In most

58 plants, organelle genomes of both the chloroplast and mitochondrion are maternally inherited

59 (Corriveau \& Coleman, 1988; Zhang, Liu \& Sodmergen, 2003), and provide a useful trace of

60 seed introduction during colonization. We hypothesize that the mesic and xeric genotypes are the

61 result of at least two separate seed (maternal) introductions to California from the native range.

62 We sought to characterize the geographic distribution and the degree of spatial overlap of these

63 introductions within California. As A. barbata is highly selfing, pollen movement is limited and

64 recombination is restricted until a new genotype arrives in the population via seed (maternal)

65 gene flow. Limited seed migration would tend to restrict levels of spatial intermixing, and we

66 expected that for a selfing species most genetic diversity would occur amongst rather than within

67 populations (Hamrick \& Godt, 1996). We assayed a wider panel of individuals across California

68 sampled from both within and amongst populations to assess the validity of this expectation.

69 Future studies using nuclear loci will examine the degree of recombination among genotypes in

70 California. In order to rule out novel polyploid formation in an invader (often a result of

71 hybridization (Novak, Soltis \& Soltis, 1991; Daehler \& Strong, 1997)), we estimated the ploidy

72 of a subset of accessions from both ranges using flow cytometry. As a cpDNA phylogeny of most

73 of the species in the genus Avena is available (based on the trnL-F/trnF-R intergenic region -

74 (Peng et al., 2010), we placed a root to our own cpDNA tree with a direct comparison of

75 chloroplast sequence data and ploidy estimates. 
76 Methods

77 Source of material

78 Old World accessions of A. barbata were donated by Agriculture Canada's Plant Genome

79 Resources of Canada (PGRC) germplasm station in Saskatoon, Saskatchewan, Canada, and the

80 USDA National Small Grains Collection (NSGC) in Aberdeen, Idaho, USA. We attempted to

81 obtain accessions from across $A$. barbata's range in the Old World, but with particular emphasis

82 on the Iberian Peninsula (Spain and Portugal) as this is thought to be the origin of Californian $A$.

83 barbata (Jain \& Marshall, 1967; Garcia et al., 1989; Minnich, 2008). Official repository

84 accession names, our own sample code names, GenBank accession numbers along with sampling

85 locations and other information are given in Supplementary Material1a.

86 In May 2010, we carried out an extensive geographic survey of $A$. barbata sites in

87 California, USA. We collected seeds from 95 sites matching locations described in three

88 dissertations (Clegg, 1972; Miller, 1977; Hutchinson, 1982) that studied allozyme variation in the

89 1970s. These sites represent the full range of growing conditions for A. barbata, and will be used

90 for future studies comparing present day to past genotypic composition. We walked $\sim 3-5$ metres

91 between each individual at a collection site to avoid sampling close relatives. In addition, we

92 included in the analysis the mesic and xeric accessions used by Gardner \& Latta (2006) to create

93 a genetic mapping population of $A$. barbata - these seeds were kindly provided by P. Garcia from

94 collections made in California during the 1980s, and had previously been genotyped using the

95 original set of five allozyme loci (Latta et al., 2004). Seeds were germinated following our lab's

96 standard protocol (Latta et al., 2004), and then planted in the greenhouse at Dalhousie University.

97 Californian populations were grown in June 2010 and June 2011, while seeds from germplasm

98 repositories were grown in June 2011 and June 2012.

99

100

101

102

103

104

105

106

107

108

109

110

111

112

113

114

\section{5}

\section{Ploidy assessment}

Forty-eight accessions from the Old World, and 24 Californian individuals were assayed for ploidy via flow cytometry. Flow cytometry was performed with a BD FACSCalibur flow cytometer at the University of Guelph, Ontario, Canada with CellQuest Pro software (BD Biosciences, San José, USA). All assays came from fresh leaf tissue harvested from young plants $(10-20 \mathrm{cms}$ in height) from the greenhouse at Dalhousie University and were shipped to Guelph in moist paper towels. Sample preparation was modified slightly from a previous protocol (Dolezel et al., 2007). The DNA content standard used was Vicia faba (26.90 pg/2C) (Doležel, Cíhalíková \& Lucretti, 1992). Approximately $0.5 \mathrm{~cm}^{2}$ of $V \cdot f a b a$ and $1.2 \mathrm{~cm}^{2}$ of $A$. barbata were chopped with a razor blade, and sat in cold extraction buffer for staining $(100 \mu \mathrm{g} / \mathrm{ml}$ propidium iodide and $50 \mu \mathrm{g} / \mathrm{ml}$ RNAse - in this study LB01 buffer was used (Dolezel et al., 2007)). The FL2 peak analysis program was used to infer ploidy from $2 \mathrm{C}$ DNA content measurements of each individual against the DNA content standard. To examine whether there was any difference in DNA content ( $\mathrm{pg} / 2 \mathrm{C})$ between California and the Old World, we performed a one-way twosample randomization test based on 1000 Monte-Carlo re-samplings of the approximate distribution using the R-package 'coin' (Zeileis et al., 2008). 
To create the phylogeny, we obtained cpDNA sequences from 49 Old world and 32

117 Californian accessions, which included two Mesic and two Xeric standards (the parents of the

118 mapping population described in Latta et al. (2004)). We chose California sites that formed

119 North-South and East-West transects by choosing at least one accession from sites previously

120 sampled by Clegg (1972) and Hutchinson (1982). DNA extraction was carried out from leaf

121 tissue following a slightly modified protocol of plant DNA extraction (Dellaporta, Woods \&

122 Hicks, 1983); we also employed an expedient protocol optimized for seeds (Ivanova, Fazekas \&

123 Hebert 2008) for 10 samples.

124 We used seven previously described primer pairs (Ebert \& Peakall 2009), Taberlet et al.

125 (1991) for the large single copy (LSC) region of the chloroplast (Table 1). All PCR products were

126 visualized on a $1.5 \%$ agarose TAE gel run at $60 \mathrm{~mA}, 100 \mathrm{~V}$ for approximately 1.5 hours. Sanger

127 cycle-sequencing reactions for PCR products with single, clear bands were carried out by

128 MacrogenUSA Inc. For each primer pair, we used only the forward primer for sequencing, with

129 the exception of the trnT-F/trnL-R fragment, which was bi-directionally sequenced. To infer a

130 root for our final phylogeny we screened one individual from each cpDNA haplotype using trnL-

131 F/trnF-R (Taberlet et al. 1991), and compared this to Peng et al.'s (2010) phylogeny of the genus

132 Avena.

133 To assess the distribution of haplotypes in the introduced range, we expanded our

134 screening to more accessions within California, using single strand conformational polymorphism

135 (SSCP). SSCPs are an efficient, and cost-effective method for screening many samples that

136 isolate single nucleotide polymorphisms (SNPs) (Gasser et al. 2007). SSCPs were used for two

137 chloroplast intergenic regions that displayed variation within California. Two Californian

138 haplotypes were separated by a SNP at the intergenic region spanning atpB and $r b c L$. A third

139 Californian haplotype differed from the first two at several loci of which we screened an indel for

140 the intergenic region between $p s a I$ and $y c f 4$. We performed double restriction digest of locus

141 atpB-rbcL amplicons, with HpaII and RsaI, and of locus psaI-ycf4 with SspI and AluI. These

142 enzymes were chosen from the chloroplast sequence data to isolate the SNP and indel into

143 smaller fragments conducive to SSCP assays. The fragments from double digests were denatured

144 for 10 minutes at $95^{\circ} \mathrm{C}$, snap frozen, and run on non-denaturing polyacrylamide gels for 17.5

145 hours at $502 \mathrm{~V}, 14 \mathrm{~mA}$, and a constant wattage of $8 \mathrm{~W}$. We attempted to screen 5-10 accessions

146 from sites that had at least one individual sequenced for chloroplast loci, and one accession at

147 each of the remaining 71 sites. This two-level sampling scheme allowed us to evaluate the

148 potential of admixture within sites, and also broad population structure between sites in

149 California. In total, 204 samples were screened for SSCPs. All of the Californian accessions for

150 which we had already obtained chloroplast sequence data were also assayed with SSCPs, and we

151 confirmed the accuracy of SSCP to relevant loci (Supplementary Materials $1 \& 2$ ).

\section{Analysis}

153 Trace files for each chloroplast locus were imported to Geneious v. 5.4.4, and aligned

154 with each other using the MUSCLE algorithm within Geneious, default settings, and confirmed

155 by eye. Traces with QV scores $<20$ were discarded and not used in further analyses. Every

156 character change (SNP or single indel) for each chloroplast locus was treated as an independent 
157 binary character. The only exception was the trnL-F (UAA) locus, which had several indels of

158 multiple adjacent basepairs; these were treated as one multistate character. All polymorphic sites

159 were then used to construct a maximum-likelihood phylogenetic tree using PhyML 3.0 (Guindon

160 et al., 2010), iterated for 10,000 bootstraps. In order to doubly verify cpDNA tree topology, we

161 also constructed a Bayesian phylogenetic tree using Mr. Bayes v. 3.2. Chloroplast trace files were

162 blasted and annotated using the web server tool CpGAVAS (Liu et al., 2012) and uploaded to

163 NCBI using the web server tool - BankIt.

164 For the Californian accessions assayed with SSCPs, we modeled the relative frequency of 165 chloroplast haplotype at a site with respect to latitude using a generalized linear binomial model

166 using the R package 'Ime4' (Bates et al., 2008). For this approach, any samples in the same

167 population were treated as non-independent observations. Within California we estimated the

168 overall $\mathrm{F}_{\text {ST }}$ for individuals at geographic sites assayed with SSCPs $(\mathrm{n}=204)$.

169 Results

170 Ploidy estimations

171 Flow cytometry gave 2C DNA content clustered at values of 8, 16 and $24 \mathrm{pg}$, (Table 2)

172 implying variation in ploidy. A. barbata is tetraploid and $16 \mathrm{pg}$ was the most common $2 \mathrm{C}$ content,

173 so accessions that had approximately $8 \mathrm{pg}$ and $24 \mathrm{pg}$ were inferred to be diploids and hexaploids,

174 respectively. These genome size estimates are well within previously reported estimates of other

175 Avena species (Bennett \& Leitch, 2005). All Californian accessions were tetraploid. However, we

176 observed six diploid and two hexaploid accessions among the 48 old world accessions. The

177 ranges of the genome size ( $\mathrm{pg} / 2 \mathrm{C})$ of Californian and tetraploid Old World accessions overlapped

178 (Table 2), but Californian accessions have approximately 1.5\% smaller genomes on average than

179 tetraploids from the old world (permutation test $Z=3.9626, p=0.00001$ ) (Fig. 1). Inferred ploidy

180 is mapped onto our phylogeny (Fig.2).

181 Phylogeography in the Old World

182 From seven chloroplast loci, we obtained $3250 \mathrm{bp}$ of chloroplast sequence from which we

183 found a total of 18 different cpDNA haplotypes across $A$. barbata's range (Figure 2A \& B).

184 Overall, there was very little cpDNA variation, and total chloroplast sequence divergence was

$1850.86 \%$ for all accessions in our phylogeny. Of the roughly six major clades in our phylogeny four

186 were well supported (bootstrap support proportion of 75 or greater). However, the different

187 haplotypes within each of these major clades were not well differentiated from each other with

188 polytomies occurring in each clade (Fig. 2B). The most widely distributed haplotype in the Old

189 World matched that of the mesic genotype. A haplotype matching that of the xeric genotype was

190 very closely related to the mesic, being separated by only a single SNP. The xeric haplotype was

191 present in three Mediterranean sites - for consistency, we refer to these haplotypes as "mesic"

192 and "xeric". Most other Old World haplotypes were unique single point occurrences (in Fig. 2A

193 we label these as "singleton tetraploids"), with the exception of the identical haplotypes isolated

194 from accessions in Portugal (CN 25800), Corsica, France (PI 337963), and Tunisia (CN 19364).

195 Three diploid Spanish accessions belonged to one well-supported clade closely related to

196 tetraploid Algerian accessions. The trnL-F/trnF-R sequences for these clades closely matched 
197 trnL-F/trnF-R sequences for the diploid Avena lusitanica, and the diploid Avena damascena,

198 respectively (Peng et al. 2010). We therefore root our tree to these groups.

The other three diploids from Greece, Spain, and Morocco are basal to the clade

200 containing the mesic and xeric haplotypes, along with other tetraploids (Fig. 2A \& B). The trnL-

$201 \mathrm{~F} / \mathrm{trnF}-\mathrm{R}$ sequence of these diploids matches those of $A$. hirtula and A. barbata, which had

202 identical trnL/trnF sequences in Peng et al. (2010) A. hirtula is the inferred diploid A genome

203 ancestor of the AB tetraploid A. barbata (Allard et al., 1993). We suggest the diploid accessions

204 in this clade are likely A. hirtula.

205 The two hexaploids (found in Iraq and Egypt) had the same haplotype, which is also basal

206 to the main clade. These two hexaploids do not match the $\operatorname{trn} L-F$ sequences of hexaploid $A$.

207 fatua (or any other Avena species) from Peng et al.'s (2010) phylogeny. Finally, all haplotypes in

208 the main tetraploid clade containing the mesic and xeric haplotypes have trnL-F sequences

209 matching those of Peng et al. (2010) A. barbata sequences.

\section{Introductions and population structure in California}

211 Three chloroplast haplotypes were identified in California. All three of these were also

212 observed in the Old World (Figs. 2 \& 3). The xeric and mesic haplotypes were of course present

213 in California, given their association with the mesic and xeric allozyme genotypes of Allard et al.

214 (1972). However, a third haplotype was found at sites in Northern California. One accession

215 collected from Livorno, Italy had a chloroplast haplotype identical to that of this "Northern"

216 haplotype (Fig. 2A), and this haplotype was distantly related to the mesic and xeric haplotypes.

217 The SSCP approach we used was able to differentiate between mesic and xeric

218 haplotypes, and northern and mesic haplotypes, (supp. Material). The SSCPs revealed 106

219 accessions possessing the xeric allele at marker ANU 67-L/68-R, distributed mostly at southern

220 latitudes (Fig. 3A \&B). We then were able to further differentiate 74 accessions that had the 221 mesic allele from 24 Northern alleles at marker ANU 73-L/ANU 74-R in California (Fig. 3B).

222 Chloroplast sequence divergence $=0.28 \%$ for Californian haplotypes, in comparison with $0.86 \%$

223 sequence divergence of all accessions, which is more than a $3 \mathrm{x}$ reduction in sequence divergence

224 for Californian haplotypes.

225 Of the 24 sites that were screened for more than one individual, 12 of these sites were

226 polymorphic (Fig. 3B). However, there is substantial spatial structure as to how this variation is

227 distributed in California. We estimated $\mathrm{F}_{\mathrm{ST}}=0.33$ based upon haplotype frequencies. Our

228 generalized linear binomial mixed model indicates a latitudinal cline in the distribution of

229 haplotypes $(\beta=-0.34, p<0.0001)$ (Fig. 3A). The xeric haplotype is more likely to occur at sites

230 in southern California, while northern locations show a higher frequency of the other two

231 haplotypes.

\section{Discussion}

233 Evidence from cpDNA sequences point to a minimum of three introductions from the Old

234 World to California. We had originally expected at least two introductions because of the two

235 previously described genotypes (Clegg \& Allard, 1972), and indeed, separate introductions of the

236 mesic and xeric allozyme genotypes are seen. However we also discovered a third haplotype that 
237 was mostly confined to Northern California. All three haplotypes in California are also observed

238 in the western Mediterranean, indicating that there was a minimum of three distinct lineages

239 introduced to California. The presence of multiple genotypes is a necessary precondition for

240 recombination to contribute to adaptation/colonization success in the new range (Ellstrand \&

241 Schierenbeck, 2000).

242 The haplotypes within California show substantial large-scale among population structure

243 largely due to a statewide a shallow North-South cline (Fig. 3a). There are xeric haplotypes at

244 Northern latitudes California, though their distribution is largely concentrated at southern

245 latitudes. Mesic haplotypes are found mostly in the Northern region of California, but they are

246 also found at many southern sites. This gradual cline of xeric haplotypes indicates that residual

247 population structure remains from the 1970s, where during this time period xeric allozyme

248 genotypes were predominant throughout California, and especially at southern latitudes (Clegg \& 249 Allard, 1972).

250 But there is also clear spatial mixing within populations. The presence of different

251 haplotypes within populations increases the probability that hybrid recombination could occur

252 through occasional outcrossing between different selfing lineages of $A$. barbata. At the within

253 population level, spatial mixing of cpDNA lineages occurs most frequently in North-central

254 populations close to San Francisco and the surrounding Bay Area. Interestingly, the Northern

255 haplotype is quite distantly related to the other two Californian haplotypes (Fig. 2B), so it is

256 possible that it is introducing additional new nuclear alleles to the Californian populations of $A$.

257 barbata, (not present in the mesic and xeric genotypes) from which additional new recombinant

258 genotypes may be emerging. The occurrence of all three genetic lineages within populations;

259 (e.g., Geyserville, Bodega Bay, Marshall, and San Ardo) allows for the possibility that

260 recombination could greatly enhance genetic variation.

261 The three introductions to California may have occurred at different times or concurrently.

262 With too little divergence time having passed since the presumed original A. barbata introduction

263 to California ( 200 years ago) (Jain \& Marshall, 1967; Minnich, 2008), only small differences in

264 our chosen cpDNA loci (i.e., no mutations have occurred in California, which would allow us to

265 track movements within the invaded range), it is impossible to infer from the phylogeny which

266 introduction came first. However, our previous field studies of the allozyme genotypes and their

267 recombinants suggest that mesic genotypes have higher fitness than the xeric type (Latta, 2009).

268 This leads to the prediction of the spread of genotypes derived from the mesic haplotype into

269 areas formerly occupied by the xeric, especially in the northern region of California (Latta, 2009).

270 This would suggest that the mesic was introduced after the xeric.

271 Since neither multi-locus allozyme combination occurred in the old world (Garcia et al.,

272 1989), the allozyme combinations described by Allard et al (1972) were thought to be

273 recombinants of alleles present in Spanish populations. These findings support the idea that

274 recombination is relevant to colonization and that it contributes to adaptation. However, if these

275 recombinant allozyme combinations were separately introduced to California, as we speculate

276 above, then hybridization may have occurred in A. barbata populations colonizing habitats

277 further south in South or Central America which were subsequently transported to California

278 (Blumler, 2000). We cannot discern whether this initial recombination might have happened in 
279 California, or prior to arrival, because our geographic sampling is restricted to North America and

280 the Mediterranean Basin. Further, as there were no new cpDNA haplotype mutants observed in

281 California since leaving the Old World we would not be able to track the route of recombination

282 or migration.

283 While flow cytometry data show that all Californian populations (accessions) are

284 tetraploid, one conspicuous result was that the genome sizes ( $\mathrm{pg} / 2 \mathrm{C}$ values) of Californian

285 tetraploid individuals were on average smaller $(\sim 1.5 \%)$ than those of the Old World tetraploid

286 individuals. It has been demonstrated that a reduced genome size for plants is adaptive in novel or

287 stressful environments (as would be experienced during an invasion) and is associated with a

288 number of phenotypic traits, such as rapid cell division during stem elongation, that facilitate

289 invasion in Phalaris arundinacea (reed canarygrass) (Lavergne, Muenke \& Molofsky, 2009).

290 Some have argued that intraspecific variation may be an artifact of measurement error

291 (Greilhuber 1998; Dolezel \& Bartos 2005). But our samples were grown under similar conditions

292 and measured on the same machine, at the same time, with the same size standards. We therefore

293 think that these highly statistically significant differences between Old World and Californian

294 oats are genuine and worth further testing the hypothesis of reduced genome size in an invading

295 population ( Lavergne, Muenke \& Molofsky, 2009).

296 Old World

297 Our main purpose in examining the Old World was to determine the number and 298 divergence of lineages introduced to California. While our Old World sampling was not 299 intensive, it was more than sufficient to identify the main branches of the phylogeny (Nielsen \& 300 Slatkin 2013). The mesic haplotype was widespread and the most commonly found haplotype in 301 the Old World - occurring as far east as India and as far west as coastal Portugal. Based on our 302 hypothesized rooting of our cpDNA tree, with the diploid A. lusitanica haplotypes, the mesic 303 haplotype also appears to be one of the most derived. This is the opposite of what is predicted 304 under coalescent theory, with the baseline expectation being that the most abundant and/or 305 widespread haplotype is usually basal (Templeton, Routman \& Phillips, 1995). This pattern 306 suggests a recent and rapid spread of $A$. barbata individuals bearing the mesic cpDNA haplotype. 307 Such a spread may have occurred if rapid expansion of the species range in the Old World had 308 reduced genetic drift creating one widespread and abundant haplotype, as well as an excess of 309 rare haplotypes (Excoffier, Foll \& Petit, 2009), and our data appear to fit these expectations. Although the large majority of our Old World accessions were tetraploid, a few were not.

312 labeled as "A. barbata", we used Peng et al. (2010) trnL-F phylogeny of Avena species to infer a 313 plausible root (Avena lusitanica) consistent with the larger Avena phylogeny. The Avena samples 314 we investigated in the Old World seem to be part of a polyploidy complex or a series of repeated 315 polyploidizations with multiple origins, which is not uncommon for plants (Soltis \& Soltis 1999; 316 Soltis et al. 2007; Husband, Baldwin \& Suda, 2013). Near the hypothesized root of our tree, the 317 Algerian samples from Djelfa and Batna are most closely related to the diploid Avena damascena 318 sequences from Peng et al. (2010), yet our accessions are tetraploid, so we refer to these 319 accessions as Avena damascena-like (Fig. 2B). We hypothesize that these tetraploids could 
320 potentially be an intermediate between the diploid Avena damascena (2x) and the derivative

321 hexaploid Avena fatua (6x), based the placement of these species in Peng et al. (2010)

322 phylogenies. Our phylogeny contains no accessions that matched the $\operatorname{trn} L-F-t r n F-R$ sequence of

323 A. fatua. The only hexaploids from our phylogeny were found in Iraq and Egypt, and are closely

324 related to the tetraploid Northern A. barbata haplotype and they are distantly related to hexaploid

325 A. fatua from Peng et al. (2010).

326 The Northern haplotype is tetraploid, but quite divergent in cpDNA sequence from the mesic

327 and xeric haplotypes. One could argue that the Northern haplotype could be another tetraploid oat

328 species such as $A$. abyssinica or A. vaviloviana, which cluster closely with $A$. barbata and have

329 identical trnL-F sequences (Peng et al., 2010). However, it is difficult to separate the whole $A$.

330 barbata/abyssinica/vaviloviana group and some authors have proposed it should all be

331 considered $A$. barbata (Rajhathy \& Thomas, 1974). These inferences, while worth revisiting to

332 clarify phylogeographic hypotheses, are speculative, and were not the main focus of our study.

333 Whether the Northern cpDNA haplotype is considered a separate species capable of hybridizing

334 with A. barbata, or a distant lineage within one species complex does little to alter our main

335 conclusion that there were three genetic lineages introduced to California. Within California

336 there is almost certainly intermixing between the three introductions, especially in the North due

337 to the presence of multiple haplotypes within populations. This sets up the possibility to test for

338 recombination between the three different introductees, and the possible adaptive spread of a new

339 recombinant genotype(s) to novel environments.

340 Acknowledgments: We thank Dr. Harold Bockelman from the USDA Small Grains Collection 341 and Dr. Dallas Kessler from Agriculture Canada at Plant Genome Resources Canada (PGRC) for 342 supplying the Old World germplasm. We are grateful to the Marine Gene Probe Laboratory at 343 Dalhousie University for help with SSCPs analysis. We are indebted to Dr. Brian Husband and 344 Paul Kron for help with flow cytometry. We also thank two anonymous reviewers from Axios 345 Review for helpful comments. 


\section{Supporting Information}

347 Supplementary Material 1 (a-c) Tables of Genbank Accession numbers for accessions screened

348 for chloroplast loci and chloroplast haplotype, and genome size information.

349 Supplementary Material 2 Table of Californian haplotypes screened with SSCP. 
References

351

352

353

354

355

356

357

358

359

360

361

362

363

364

365

366

367

368

369

370

371

372

373

374

375

376

377

378

379

380

381

382

383

Allard RW, Babbel GR, Clegg MT, Kahler AL. 1972. Evidence for coadaptation in Avena barbata. Proceedings of the National Academy of Sciences of the United States of America 69:3043-3048

Allard RW, Garcia P, Saenz-de-Miera LE, de la Vega MP. 1993 Evolution of multilocus genetic structure in Avena hirtula and Avena barbata. Genetics 135:1125-1139

Baker HG. 1955. Self-compatibility and establishment after"long-distance"dispersal. Evolution 9:347-349

Baker HG. 1967. Support for Baker's law-as a rule. Evolution 21:853-856

Barrett S, Colautti RI. 2008 Plant reproductive systems and evolution during biological invasion. Molecular Ecology 17:373-383

Bates D, Maechler M, Dai B (2008) The lme4 package. Computer software manual. Retrieved from http://cran. r-project. org/web/packages/lme4/lme4. pdf.

Bennett MD, Leitch IJ. 2005. Nuclear DNA amounts in angiosperms: progress, problems and prospects. Annals of Botany 95:45-90

Blumler MA. 2000. Spatial analysis to settle an unresolved question in genetics, with both theoretical and applied implications. Research in Contemporary and Applied Geography: A Discussion Series 24:1-42

Clegg MT, Allard RW. 1972. Patterns of genetic differentiation in the slender wild oat species Avena barbata. Proceedings of the National Academy of Sciences of the United States of America 69: 1820-1824

Clegg MT. 1972. Patterns of Genetic Differentiation in Natural Populations of Wild Oats. Doctoral Dissertation. University of California, Davis.

Corriveau JL, Coleman AW. 1988. Rapid screening method to detect potential biparental inheritance of plastid DNA and results for over 200 angiosperm species. American Journal of Botany 75:1443-1458

Daehler C, Strong D. 1997. Hybridization between introduced smooth cordgrass (Spartina alterniflora; Poaceae) and native California cordgrass (S. foliosa) in San Francisco Bay, California, USA. American Journal of Botany, 84:607-611

Dellaporta SL, Wood J, Hicks JB. 1983. A plant DNA minipreparation: version II. Plant molecular biology reporter 1:19-21

Dlugosch K, Parker M. 2008. Founding events in species invasions: genetic variation, adaptive evolution, and the role of multiple introductions. Molecular Ecology 17: 431-449

Doležel J, Bartos J. 2005. Plant DNA flow cytometry and estimation of nuclear genome size. 
Annals of Botany 95:99-110

385

386

387

388

389

390

391

392

393

394

395

396

397

398

399

400

401

402

403

404

405

406

407

408

409

410

411

412

413

414

415

416

417

418

Doležel J, Greilhuber J, Suda J. 2007. Estimation of nuclear DNA content in plants using flow cytometry. Nature Protocols 2:2233-2244

Doležel J, Cíhalíková J, Lucretti S. 1992. A high-yield procedure for isolation of metaphase chromosomes from root tips of Vicia faba L. Planta 188:93-98

Ebert D, Peakall R. 2009. A new set of universal de novosequencing primers for extensive coverage of noncoding chloroplast DNA: new opportunities for phylogenetic studies and cpSSR discovery. Molecular Ecology Resources 9:777-783

Ellstrand NC, Schierenbeck KA. 2000. Hybridization as a stimulus for the evolution of invasiveness in plants? Proceedings of the National Academy of Sciences of the United States of America 13:7043-7050

Excoffier L, Foll M, Petit RJ. 2009. Genetic Consequences of Range Expansions. Annual Review of Ecology, Evolution, and Systematics 40:481-501

Garcia P, Vences F, de la Vega MP, Allard RW. 1989. Allelic and Genotypic Composition of Ancestral Spanish and Colonial Californian Gene Pools of Avena barbata: Evolutionary Implications. Genetics 122:687-694

Gasser RB, Hu M, Chilton NB, Campbell BE, Jex AJ, Otranto D, Cafarchia C, Beveridge I, Zhu X. 2007. Single-strand conformation polymorphism (SSCP) for the analysis of genetic variation. Nature Protocols 1:3121-3128

Greilhuber J. 1998. Intraspecific variation in genome size: a critical reassessment. Annals of Botany 82:27-35

Guindon S, Dufayard J-F, Lefort V, Anisimova M, Hordjik, Gascuel O. 2010. New algorithms and methods to estimate maximum-likelihood phylogenies: assessing the performance of PhyML 3.0. Systematic Biology 59:307-321

Hamrick JL, Godt MJW. 1996. Effects of Life History Traits on Genetic Diversity in Plant Species. Philosophical Transactions of the Royal Society B: Biological Sciences 351:12911298

Hamrick JL, Holden LR. 1979. Influence of microhabitat heterogeneity on gene frequency distribution and gametic phase disequilibrium in Avena barbata. Evolution 33:521-533

Husband BC, Schemske DW. 1996. Evolution of the magnitude and timing of inbreeding depression in plants. Evolution 50:54-70

Husband BC, Baldwin SJ, Suda J. 2013. The Incidence of Polyploidy in Natural Plant Populations: Major Patterns and Evolutionary Processes. In: Plant Genome Diversity Volume 2, pp. 255-276. Springer Vienna, Vienna.

Hutchinson ES. 1982. Genetic Markers and Ecotypic Differentiation of Avena barbata Pott ex 
Link. Doctoral Dissertation. University of California, Davis.

420

421

422

423

424

425

426

427

428

429

430

431

432

433

434

435

436

437

438

439

440

441

442

443

444

445

446

447

448

449

450

451

452

Hutchinson ES, Price S, Kahler A, Allard RW. 1983. An experimental verification of segregation theory in a diploidized tetraplold: esterase loci in Avena barbata. Journal of Heredity 74:381-383

Ivanova NV, Fazekas AJ, Hebert PD. 2008. Semi-automated, Membrane-Based Protocol for DNA Isolation from Plants. Plant molecular biology reporter 26:186-198

Jain SK, Marshall DR. 1967. Population studies in predominantly self-pollinating species. X. Variation in natural populations of Avena fatua and A. barbata. American Naturalist 101:1933

Johansen-Morris AD, Latta RG. 2006. Fitness consequences of hybridization between ecotypes of Avena barbata: hybrid breakdown, hybrid vigor, and transgressive segregation. Evolution 60:1585-1595

Johansen-Morris AD, Latta RG. 2008. Genotype by environment interactions for fitness in hybrid genotypes of Avena barbata. Evolution 62:573-585

Latta RG. 2009. Testing for local adaptation in Avena barbata: a classic example of ecotypic divergence. Molecular Ecology 18:3781-3791

Latta RG, MacKenzie J, Vats A, Schoen D. 2004. Divergence and variation of quantitative traits between allozyme genotypes of Avena barbata from contrasting habitats. Journal of Ecology 92:51-71

Lavergne S, Muenke NJ, Molofsky J. 2009. Genome size reduction can trigger rapid phenotypic evolution in invasive plants. Annals of Botany 105:109-116

Le Roux JJ, Wieczorek AM, Wright MG, Tran CT. 2007. Super-Genotype: Global Monoclonality Defies the Odds of Nature. PLoS ONE 2:e590

Liu C, Shi L, Zhu Y, Chen H, Zhang J, Lin X, Guan X. 2012. CpGAVAS, an integrated web server for the annotation, visualization, analysis, and GenBank submission of completely sequenced chloroplast genome sequences. BMC Genomics 13:715

Marshall DR, Allard RW. 1970. Maintenance of Isozyme Polymorphisms in Natural Populations of Avena barbata. Genetics 66:393-399

Miller RD. 1977. Genetic Variability in the Slender Wild Oat Avena barbata in California. Doctoral Dissertation. University of California, Davis.

Minnich R. 2008. California's Fading Wildflowers. University of California Press, Berkeley and Los Angeles.

Nielsen R, Slatkin M. 2013. An Introduction to Population Genetics: Theory and Applications. Sinauer Associates, Sunderland, MA. 
453

454

455

456

457

458

459

460

461

462

463

464

465

466

467

468

469

470

471

472

473

474

475

476

477

478

479

Novak SJ, Soltis DE, Soltis PS. 1991. Ownbey's Tragopogons: 40 Years Later. American Journal of Botany, 78:1586-1600

Peng Y-Y, Wei Y-M, Baum BR, Jiang QT, Lan XJ, Dai SF, Zheng YL. 2010. Phylogenetic investigation of Avena diploid species and the maternal genome donor of Avena polyploids. Taxon, 59, 1472-1482

Prentis PJ, Wilson JRU, Dormontt EE, Richardson DM, Lowe AJ. 2008. Adaptive evolution in invasive species. Trends in Plant Science 13:288-294

Price SC, Jain SK. 1981. Are inbreeders better colonizers? Oecologia 49:283-286

Rajhathy T, Thomas H. 1974. Cytogenetics of oats (Avena L.). Ottawa : Genetics Society of Canada, 1974., Ottawa.

Schierenbeck KA, Ellstrand NC. 2009. Hybridization and the evolution of invasiveness in plants and other organisms. Biological Invasions 11:1093-1105

Soltis DE, Soltis PS. 1999. Polyploidy: recurrent formation and genome evolution. Trends in Ecology \& Evolution 14:348-352

Soltis D, Soltis P, Schemske D, Hancock JF, Thompson JN, Husband BC, Judd WS. 2007. Autopolyploidy in angiosperms: have we grossly underestimated the number of species? Taxon 56:13-30

Taberlet P, Gielly L, Pautou G, Bouvet J. 1991. Universal primers for amplification of three non-coding regions of chloroplast DNA. Plant Molecular Biology 17:1105-1109

Templeton AR, Routman E, Phillips CA. 1995. Separating population structure from population history: a cladistic analysis of the geographical distribution of mitochondrial DNA haplotypes in the tiger salamander, Ambystoma tigrinum. Genetics 140:767-782

Zeileis A, Wiel MA, Hornik K, Hothorn T. 2008. Implementing a class of permutation tests: The coin package. Journal of Statistical Software 28:1-23

Zhang Q, Liu Y, Sodmergen. 2003. Examination of the cytoplasmic DNA in male reproductive cells to determine the potential for cytoplasmic inheritance in 295 angiosperm species. Plant and Cell Physiology 44:941-951 
Figure 1

Genome sizes of tetraploid Avena species in the Old World and California

Probability density plot (grey-shaded region) and rug plot (orange hatch marks) of genome size values $(\mathrm{pg} / 2 \mathrm{C})$ for tetraploid $A$. barbata from the Old World $(n=40)$, and California ( $n=$ 24). The thick black line in the middle of each density plot is the median value for genome size. The dotted line is the overall median value. 


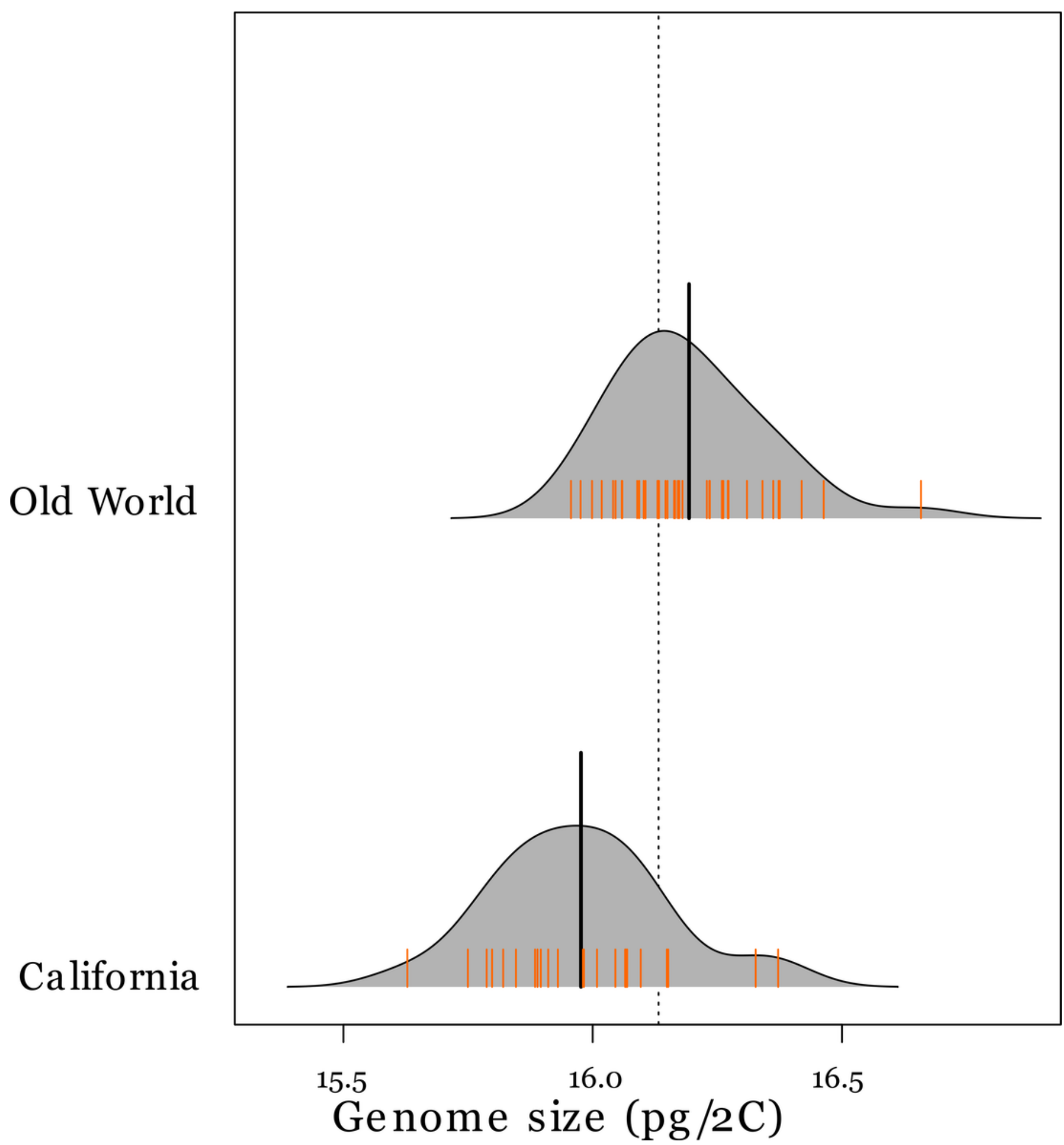




\section{Figure 2}

Map of Old World Avena accessions and cpDNA phylogeny juxtaposed with previous cpDNA phylogeny by Peng et al. (2010)

Map (Lambert azimuthal equal-area projection) of the Old World accessions (panel A). The haplotypes in colour on the map represent the accessions that occur in both the Old World and California. Maximum-likelihood phylogenetic tree based on 100,000 re-samplings (panel B). Bootstrap support is indicated at nodes. The tree was constructed using all informative chloroplast sites of seven loci. The ploidy for each haplotype is mapped onto the tree, not included as a character in the phylogeny. Inset tree is a drawn rough approximation of Peng et al.'s tree (Peng et al. 2010) for context in explaining our phylogeny's hypothesized rooting. Blue hatched marks are collapsed branches, generally within a clade. Map of broad categories chloroplast haplotypes of Old World (European and Asian) wild oat accessions. "Singleton tetraploids" are not necessarily identical to each other, but all mesic and xeric haplotypes are identical to each other. See discussion for further elaboration on $A$. damascena-like, and A. lusitanica types. 


\section{Longitude}
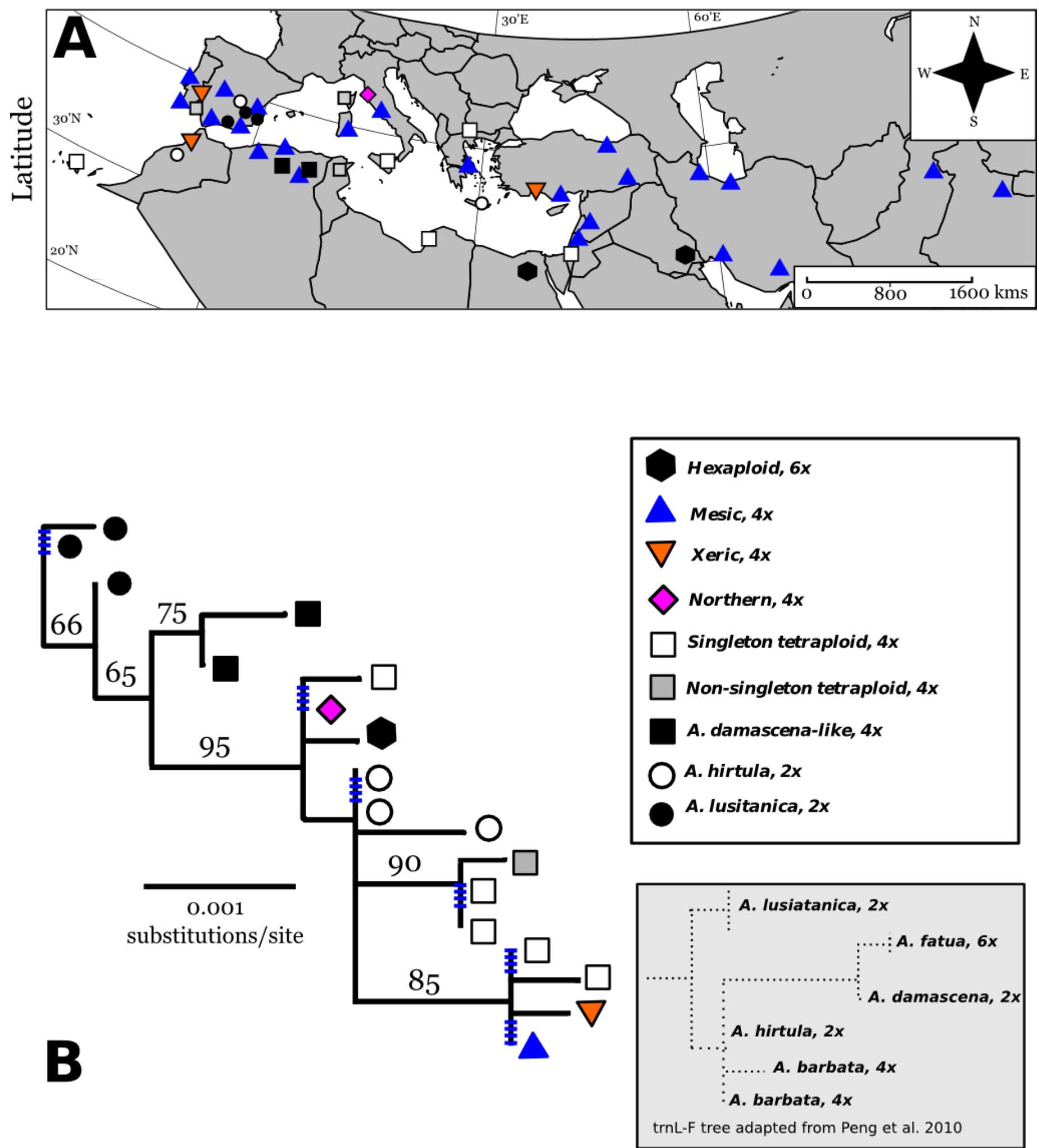


\section{Figure 3}

Linear logistic regression of latitudinal cline of cpDNA haplotypes in California

Linear logistic regression of the relative abundance of the xeric cpDNA haplotype on latitude, the $95 \%$ confidence bands based on the logistic distribution (panel A). Note the latitude is on the $y$-axis for comparison with the map. Panel B shows the geographic distribution of haplotypes in California (Lambert azimuthal equal-area projection). Pie charts represent 24 sites where multiple individuals were assayed, and are sized relative to the number of individuals sampled at a site. Triangles represent 71 sites where one individual was sampled per site.
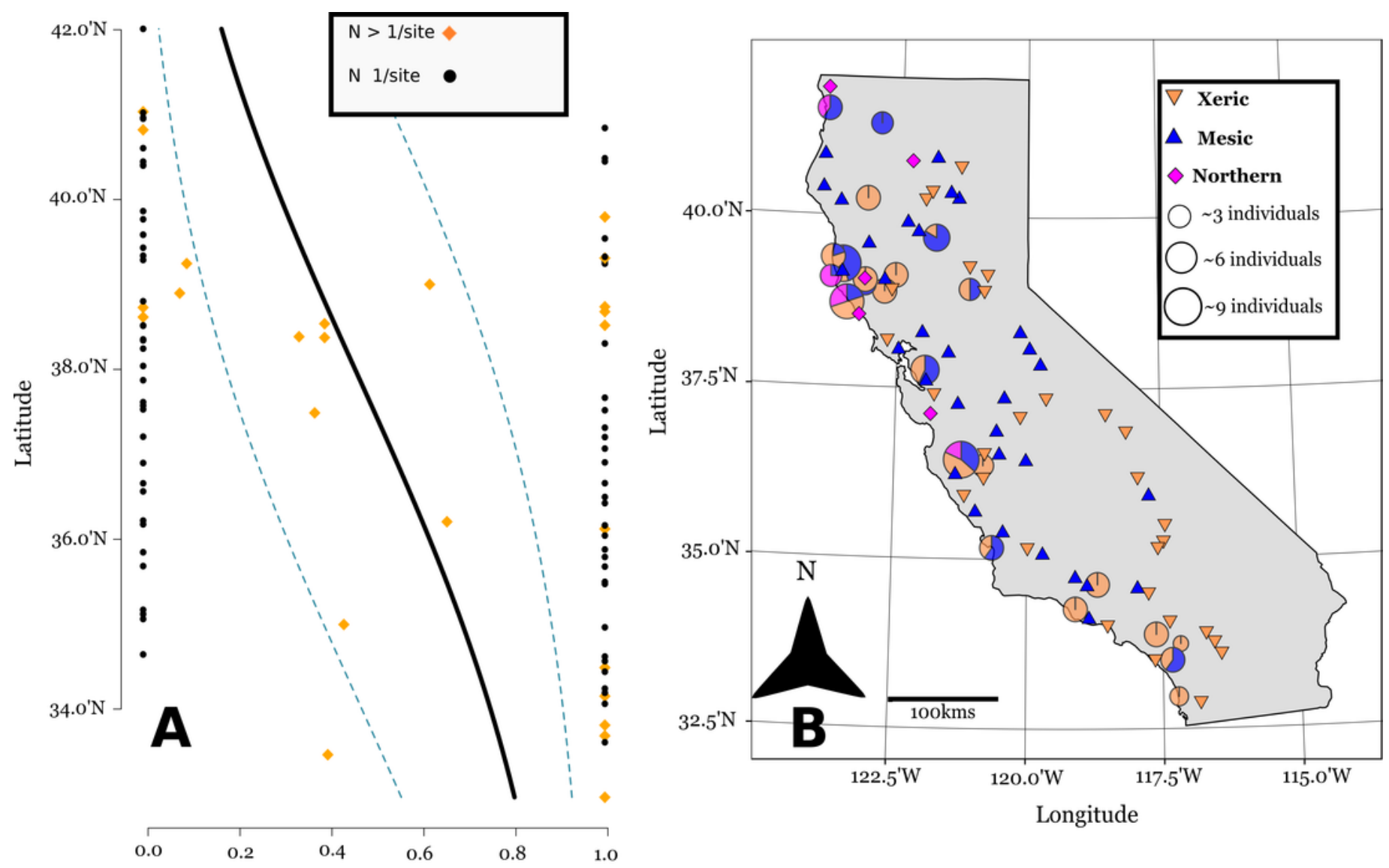

Relative Frequency of Xeric Haplotype 


\section{Table 1 (on next page)}

Summary of intergenic cpDNA loci used

Intergenic locus region target, the primer pair (as given in reference), the number of variable characters for each locus, and the length of the fragment uploaded to GenBank. Sequencing primers are underlined. The eighth and last intergenic locus (trnL (UAA) 3'exon) is italicized because we only screened unique haplotypes among accessions from our dataset to ascertain the root of our tree see Supplementary Material 1c. *These loci were used in SSCP analysis. 


\begin{tabular}{|c|c|c|c|c|}
\hline $\begin{array}{l}\text { Intergenic } \\
\text { regions } \\
\text { targeted }\end{array}$ & Primer Pair & $\begin{array}{l}\text { Number } \\
\text { of } \\
\text { variable } \\
\text { characters }\end{array}$ & $\begin{array}{l}\text { Length of } \\
\text { fragment in } \\
\text { A. barbata(bp) }\end{array}$ & Reference \\
\hline $\begin{array}{l}\text { trnQ (UUG) } \\
\text { - psbK }\end{array}$ & ANU11-L/ANU-12R & 5 & 408 & $\begin{array}{l}\text { (Ebert \& Peakall } \\
\text { 2009) }\end{array}$ \\
\hline atpB - rbcL* & ANU67-L/ANU68-R, & 7 & 901 & $\begin{array}{l}\text { (Ebert \& Peakall } \\
\text { 2009) }\end{array}$ \\
\hline psaI - ycf 4* & $\underline{\text { ANU73-L/ANU74-R }}$ & 3 & 356 & $\begin{array}{l}\text { (Ebert \& Peakall } \\
\text { 2009) }\end{array}$ \\
\hline psaJ - rpl33 & ANU83-L/ANU84-R & 1 & 221 & $\begin{array}{l}\text { (Ebert \& Peakall } \\
\text { 2009) }\end{array}$ \\
\hline rpl33 - rps18 & ANU85-L/ANU86-R & 4 & 595 & $\begin{array}{l}\text { (Ebert \& Peakall } \\
\text { 2009) }\end{array}$ \\
\hline $\operatorname{trnT}(\mathrm{UGU})$ & $\underline{\operatorname{trnT}-\mathrm{F} / \mathrm{trnL}-\mathrm{R}}$ & 4 & 510 & $\begin{array}{l}\text { (Taberlet et al. } \\
\text { 1991) }\end{array}$ \\
\hline $\begin{array}{l}\operatorname{trnL}(\text { UAA) } \\
5 \text { 'exon }\end{array}$ & $\operatorname{trnT}-\mathrm{F} / \mathrm{trnL}-\mathrm{R}$ & 4 & 259 & $\begin{array}{l}\text { (Taberlet et al. } \\
\text { 1991) }\end{array}$ \\
\hline $\begin{array}{l}\text { trnL }(U A A) \\
\text { 3'exon }\end{array}$ & trnL-F/trnF-R & 3 & 730 & $\begin{array}{l}\text { (Taberlet et al. } \\
\text { 1991) }\end{array}$ \\
\hline
\end{tabular}




\section{Table 2 (on next page)}

Summary of genome size range from flow cytometry analyses

Broad grouping of accessions evaluated with flow cytometry, number of plants assayed, mean $2 \mathrm{C}$ DNA content $(\mathrm{pg} / 2 \mathrm{C})$, the minimum and maximum range of the mean DNA content, inferred ploidy, and standard error (SE). See Supplementary Material la-b for detailed genome size information. 


\begin{tabular}{llllll}
\hline Group & Sample size & $\begin{array}{l}\text { Mean 2C } \\
\text { DNA content } \\
\text { (pg/2C) }\end{array}$ & SE & $\begin{array}{l}\text { Range of } \\
\text { 2C DNA } \\
\text { content } \\
\text { (pg/2C) }\end{array}$ & $\begin{array}{l}\text { Inferred } \\
\text { ploidy }\end{array}$ \\
\hline $\begin{array}{l}\text { All } \\
\text { Californian } \\
\text { accessions }\end{array}$ & 24 & 15.97 & 0.03 & $15.62-$ & $4 \mathrm{x}$ \\
$\begin{array}{l}\text { Tetraploid old } \\
\text { world }\end{array}$ & 40 & 16.21 & 0.03 & $15.68-16.69$ & $4 \mathrm{x}$ \\
$\begin{array}{l}\text { accessions } \\
\begin{array}{l}\text { Diploid (Clade } \\
\text { 1 - Spain) }\end{array}\end{array}$ & 3 & 8.26 & 0.05 & $8.16-8.32$ & $2 \mathrm{x}$ \\
$\begin{array}{l}\text { Diploid (Clade } \\
\text { 2-Moroco, } \\
\text { Greece, Spain) }\end{array}$ & 3 & 8.65 & 0.10 & $8.48-8.83$ & $2 \mathrm{x}$ \\
$\begin{array}{l}\text { Babylon, Iraq } \\
\text { and Giza, }\end{array}$ & 2 & & & & \\
Egypt & 24.99 & 0.56 & $24.43-25.55$ & $6 \mathrm{x}$ \\
\hline
\end{tabular}

